\title{
A Revisit to the Recent Human Error Events in Nuclear Power Plants Focused to the Organizational and Safety Culture
}

\author{
Yong-Hee Lee \\ I\&C and Human Factors Division, Korea Atomic Energy Research Institute (KAERI), \\ 1042 Daedeok-Daero, Yuseong-Gu, DaeJeon, 305-353
}

\begin{abstract}
Objective: This paper presents additional considerations related to organization and safety culture extracted from recent human error incidents in Korea, such as station blackout(i.e., SBO) in Kori\#1. Background: Safety culture has been already highlighted as a major cause of human errors after 1986 Chernobyl accident. After Fukushima accident in Japan, the public acceptance for nuclear energy has taken its toll. Organizational characteristics and culture became elucidated as a major contributor again. Therefore many nuclear countries are re-evaluating their safety culture, and discussing any preparedness and its improvement. On top of that, there was an SBO in 2012 in the Kori\#1. Korean public feels frustrated due to the similar human errors causing to a catastrophe like Fukushima accident. Method: This paper reassesses Japan's incidents, and revisits Korea's recent incidents. It focuses on the analysis of the hazards rather than the causes of human errors, the derivation of countermeasures, and their implementation. The preceding incidents and conclusions from Japanese experience are also re-analyzed. The Fukushima accident was an SBO due to the natural disaster such as earthquakes and a successive tsunami. Unlike the Fukushima accident, the Kori\#1 incident itself was simple and restored without any loss and radioactive release. However, the fact that the incident was deliberately concealed led to massive distrust. Moreover, the continued violation of rules and organized concealment of the accident are serious signs of a new distorted type of human errors, blatantly revealing the cultural and fundamental weakness of the current organization. Result: We should learn from Japanese experiences who had taken pride in its safety technology and fairly high confidence in safety culture. Japan's first criticality accident in JCO facility splashed cold water on that confidence. It has turned out to be a typical case revealing the problems in the organization and safety culture. Since Japan has failed to gain lessons and countermeasure, the issue persists to the Fukushima incident. Conclusion: Safety culture is not a specific independent element, which makes it difficult to either evaluate it properly or establish countermeasures from the lessons. It may continue to expose similar human errors such as concealment of incident and manipulation of bad data. Application: Not only will this work establish the course of research for organization and safety culture, but this work will also contribute to the revitalization of Korea's nuclear industry from the disappointment after the export contract to UAE.
\end{abstract}

Keywords: Organizational factor, Safety culture, Kori \#1, Human error, Station black-out, Nuclear power plants

Corresponding Author: Yong-Hee Lee. I\&C and Human Factors Division, Korea Atomic Energy Research Institute (KAERI), 1042 Daedeok-Daero, Yuseong-Gu, DaeJeon, 305-353.

Phone: +82-42-868-2941, E-mail: yhlee@kaeri.re.kr

Copyright@2013 by Ergonomics Society of Korea(pISSN:1229-1684 eISSN:2093-8462). All right reserved.

(c)This is an open-access article distributed under the terms of the Creative Commons Attribution Non-Commercial License(http://creativecommons.org/licenses/by-nc/3.0/), which permits unrestricted non-commercial use, distribution, and reproduction in any medium, provided the original work is properly cited. http://www.esk.orkk 


\section{A Brief Background for the Safety Culture Issue in NPPs}

시스템의 발전 과정에서 대형 복합(large-complex) 시 스템은 수많은 혜택을 주었지만, 그 혜택만큼이나 큰 위험을 내포하고 있다. 타이타닉 여객선 사고 이후 20세기에는 수 많은 대형시스템 사고로 인류의 기술적 자부심에 상처를 입 었으며, 그 중에서도 원자력 분야의 사례가 두드러진다. 원 자력 분야에서는 1979년 TMI 원전과 1986년 체르노빌 원전 사고로 세계를 충격에 빠뜨린 경험이 있고, 이는 후쿠 시마 원전 사고로 21세기에도 다시 반복되고 있다.

그런데 이러한 대표적 사건을 인재로 보고 새로운 기술적 도전과제로 삼아온 관행은 인간공학의 기술 발전 촉진에 기 여한 바가 크다. TMI 사고는 인터페이스의 문제로 인한 인 적오류로 인식한 결과, 종사자에게 적절한 정보를 제공하고 최적의 표시방법을 통해 첨단 인터페이스를 제공하는 인간 공학 기술의 획기적인 발전을 달성했다. 이는 전산기 및 첨 단 전자 기술의 발전과 결합하여 이때까지 자동차 및 항공 우주 분야를 통해 발전해오던 작업환경 및 설비에 대해 전 산업에서 획기적인 발전을 달성하는데 기여했다. 이어진 체 르노빌 사고는 같은 인적오류이지만 조직과 문화적 문제로 의해 발생한 것임을 새롭게 인식하여, 인간공학의 새로운 과 제로 안전문화(safety culture)를 부각하였다.

그러나 이후 원전에서 발생한 인적오류의 $70 \%$ 가 조직적 문제라는 통계가 계속되고 있었으며, 결정적으로 2011년 후 쿠시마 사고를 통해서 체르노빌 사고의 교훈에서 도출된 과 제가 아직 기술적으로 미결 상태임이 드러났다(Figure 1). 이는 후쿠시마 사고에 연이어 발생한 원전사건으로 대중수 용도(public acceptance)가 심각하게 악화된 상황에서 안전 문화 문제가 국내 원자력계에 큰 과제로 부각되고 있어, 일 본의 인적오류 사고 경험을 통해 해결방안을 모색하였다. 일 본은 자체 분석에서 후쿠시마 사고를 "Made-in-Japan"이 라고 설명하면서, 고유한 조직 및 문화적 특성이 사고의 확 산에 결정적인 요소로 작용했음을 자인하였다.

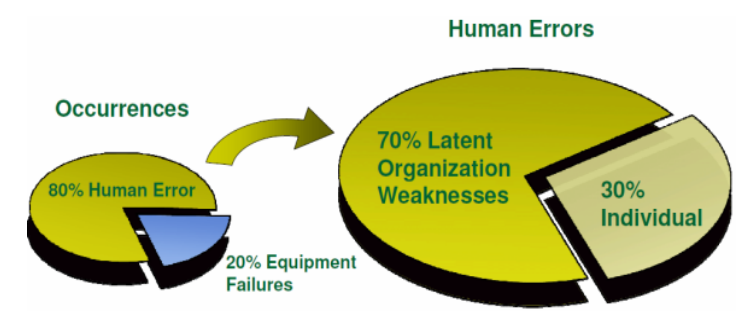

Figure 1. Composition of human error hazards in trip events
이러한 분석 결과는 안전문화의 중요성을 새롭게 불러일 으켜 전세계 원자력 국가들이 안전문화에 대한 재평가 및 조직 및 문화적 결함으로 인해 발생할 수 있는 인적오류에 대해 포착 및 대응방안 마련에 부심하게 하였다. 또 안전에 관한 우월감을 가지고 있던 일본이 근본적인 반성에 나서는 계기가 되었다.

그러나 조직 및 문화적 요소를 의미하는 안전문화는 그 정 의(definition) 부터 불확실하여, 안전성 확보 여부는 물론 문 제점 포착이나 개선대책 마련이 추상적인 수준에 머물러 있 어서 기술적인 접근이 어려운 상황이다. 본 논문은 안전문화 와 관련된 일본의 원자력 사고 경험을 추적하여, 국내 고리 1 호기 전원상실 $(\mathrm{SBO}$ : Station Black-Out) 사건과 비교하 였다. 특히 인적오류 분석 및 대응방안 도출 과정에서 안전 문화를 보다 효과적으로 다룰 수 있는 방안을 검토하였다.

\section{Revisit to the Human Error Cases in Korea}

원전은 고신뢰도의 기기, 설계 및 운영을 따르기 때문에 사고의 발생 빈도가 매우 낮다. 이러한 희귀 사고(rare event) 특성은 발생된 사례로부터 문제점의 상대적 빈도를 파악하거나 우선적 개선사항을 결정하는 일반적인 분석기법 을 적용하기가 근본적으로 어렵다. 따라서 본 논문에서는 국내에서 발생한 몇 가지 사건에서 인적오류의 특성을 도출 하였다. 분석 대상은 일반에 공개된 운전정보(OPIS)에서 인적요소와 관련하여 발생된 것으로 명시된 것이다. 이는 1996년 수행된 Lee(1996) 등의 선행 연구와 달리 인적오 류 여부 및 원인에 대한 독자적 판단을 적용하지 않았으며, 원인이 아니라 각 사례의 고유한 특성에 따른 위험요소를 파 악하는 재분석 과정을 거쳤다.

\subsection{Station black-out and its concealment in Kori \#1}

고리 1 호기에서 계획된 정비작업의 한 가지 항목인 전원 장치의 시험 과정에서 시험작업자의 인적오류가 발생하였다 (Figure 2). 고리 1호기 원전은 국내 최초의 원전이자 설계 수명을 넘어 2008년에 계속 운전을 허가를 받아 운전하고 있었다. 시험을 맡은 협력회사 직원의 단순한 시험오류에서 시작된 기능적인 실패였지만, 오류의 배경에 관리적 문제가 내포되어 있다. 특히 단순한 시험오류가 전원상실로 확산되 었으며, 전원상실 상태를 해결하기 위한 후속조치에서 몇 가 지 위반 및 은폐 등 다른 왜곡된 유형의 오류로 파급되었다. 단순실수가 전체 시스템 상황에 따라 중대한 사건으로 변화 
되는 과정을 보여주는 전형적인 사례로 분석된다.

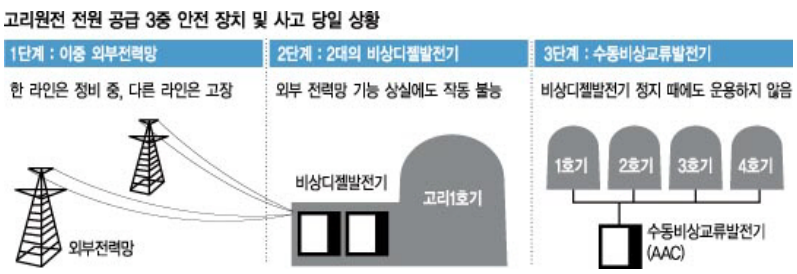

Figure 2. A Brief on Kori \#1 SBO event

이 사건에서 단순한 실수가 사회적 현안으로 급격히 비화 된 것은 사건의 발생을 보고하지 않고 내부적으로 묵살한 기 간이 상당한 기간 동안 지속되었다가 나중에 밝혀졌다는 점 때문이었다. 특히 후쿠시마 사태 이후에 최고의 관심을 받고 있는 원전의 전원상실(SBO: Station Black-Out) 사건이었 다는 점에서 매우 큰 우려를 불러일으켰다(Figure 3). 또 설 계수명 30 년을 넘어 국내 최초로 10 년간의 계속 운전을 허 가 받음으로써, 후쿠시마와 유사한 노후화 원전의 대표격이 었다는 점이 주목되었다. 따라서 비교적 단순한 종사자의 조 작실수 유형의 인적오류가 조직 내외의 다른 관리적 결함 때 문에 그 중요도가 급격히 확대되는 것을 보여주는 전형적인 사례일 뿐만 아니라, 상황에 따른 중요도의 급격한 변화 및 이어지는 위반, 조작, 은폐 등을 일으킨 전형적인 파급형 인 적오류의 사례로 분석된다.

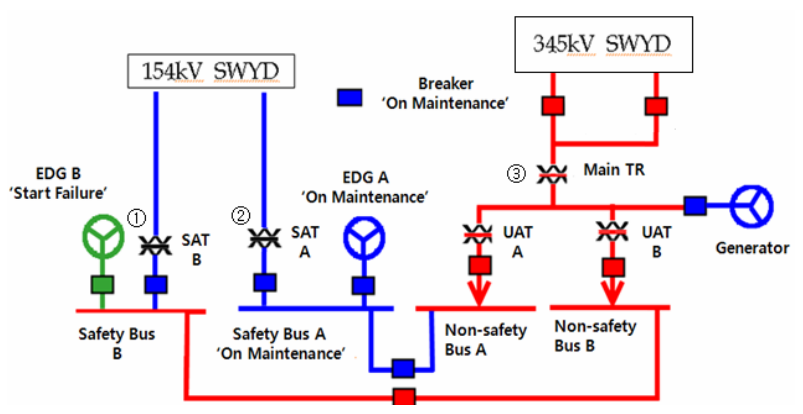

Figure 3. A scheme for Kori\#1 station black-out event

\subsection{A safety injection occurred in Shin-Kori \#1}

원전에서 예기치 않은 기기의 조합이 발생하여 사고와 비 상시를 위해 준비해놓은 안전기능을 작동하는 인적오류 사 건이 발생하였다. 장시간에 걸쳐 다양하게 벌어진 현장 및 제어실의 시험작업 과정에서 기기들의 조합이 예기치 않게 원자로 건물 살수 상태로 진행함으로써 불가피하게 안전기
능을 작동한 사건이다(Figure 4)

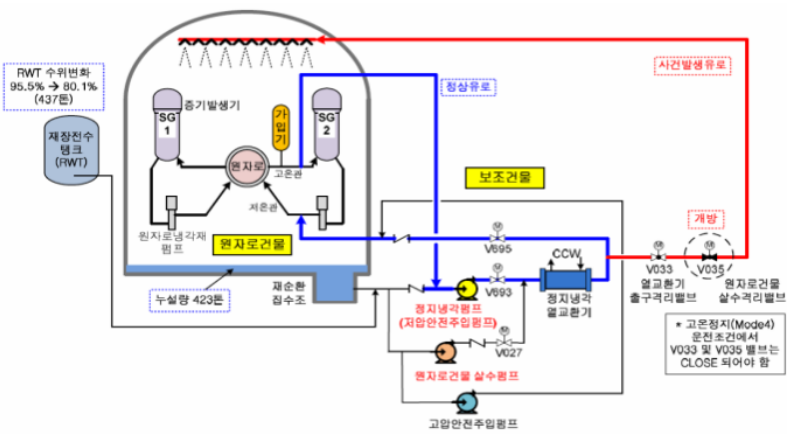

Figure 4. Overview of safety injection event in Shin-Kori \#1

안전주입 및 백색비상 등의 모든 조치는 적절했지만, 전혀 예상치 않은 불필요한 조작이 필요했다는 점에서 새로운 인 적오류로 파악된다. Figure 5에서 보는 바와 같이 그 배경에 는 설계 변경의 파급, 몇 번의 교대근무 과정에서의 사소한 간과, 시험자의 확인 누락, 종사자의 파악능력, 훈련 등 다양 한 요소들이 상당히 긴 시간에 걸쳐 결합되어 발생된 사건임 을 알 수 있다. 특히 해당 원전(신고리 1호기)은 국내에서 자립된 설계건설 기술의 최종 단계를 실증한 것이므로, 이 러한 관리적 요소들의 결합이 구조적으로 작용한 체계적 오류의 특성을 보였기 때문에 시사하는 바가 크다.

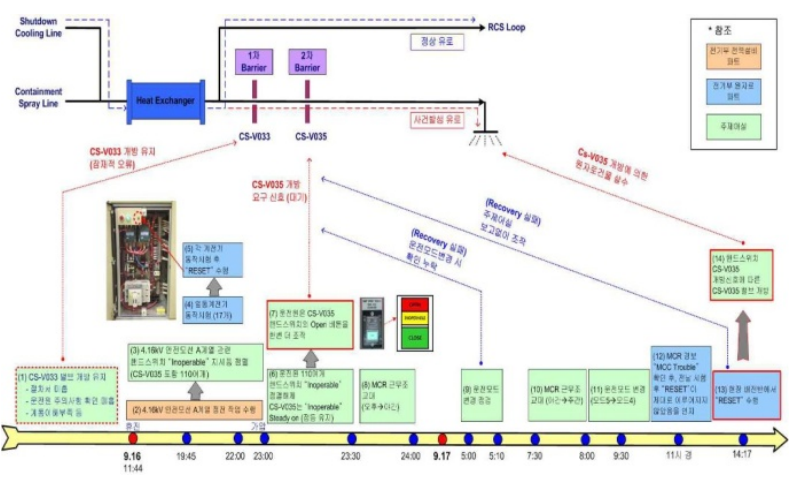

Figure 5. A schematic diagram of safety injection event

\subsection{A human error due to the digital technology}

국내 원전은 발전소의 2차측 핵심 기기인 터빈 조속기와 관련된 다수의 기기를 디지털화하면서 제어반을 획기적으로 간소화하였다. 기존 원전의 계측제어 계통에 $\mathrm{PC}$ 급 컴퓨터 기반의 디지털 기기를 활용함으로써, 30 50가지 이상의 감 
시 및 제어기능을 통합 관리하도록 설계를 개선한 것이다.

그러나 컴퓨터 기기에서 드물지 않은 비정상적인 표시 또 는 고착의 문제, 신호전송에서 발생하는 통신오류, 사용자의 습관적인 reset 조작, $\mathrm{S} / \mathrm{W}$ 설계상의 설정치 불확실 등의 문 제로 인해, 불시정지가 유발되었다.

이 사례는 운전원이 디지털 기기를 활용하여 실제 상태를 판단하는 과정에서 일어날 수 있는 상황을 잘 보여주었다. 또 종사자가 인적오류를 피하기 위해 관련 기술부서와 상당 히 적극적인 협의를 거쳤음에도 불구하고 초기 설정치와 현 재 운전 상황의 불일치와 같은 사소한 문제까지 고려할 수 없었다는 점에서 디지털화의 인적오류 위험성이 어떤 영역 으로 변화되는가를 보여주는 사례다.

\section{Experience of Safety Culture Event in Japan}

\subsection{Safety culture accidents prior to Fukushima in Japan}

1986년 체르노빌 원전 사고는 설계개념의 결함은 물론 종사자의 원자력 위험에 대한 근본적인 무지 등이 지적되면 서 구 소련의 기술적 자존심을 무너뜨린 사건이었다. 이로서 인적오류가 보다 근본적으로 조직 및 문화적 배경에서도 발 생할 수 있음을 인식하는 계기가 되었다. 따라서 IAEA는 INSAG 활동을 통해 안전문화(safety culture)라는 과제를 정의하고 전세계적인 안전문화 평가를 주도했는데, 이러한 활동의 배경에는 당시 IAEA를 주도하던 일본의 의견이 크 게 작용하였다. 산업안전의 전반에 걸쳐 기술적 자부심을 가 지고 있는 일본은 원자력의 안전문화에 관한 우월적 자신감 을 드러내고 있었다.

하지만 이러한 자신감은 1999년 JCO 핵연료 가공공장에 서 일본 최초의 임계 사고가 발생하면서 주민들을 소개하는 등 사회적으로 큰 타격을 입었다. 특히 사고의 원인이 근본 적으로 조직 및 문화적 문제라는 것이 밝혀지면서 의심을 받게 되었다. 그런데도 $\mathrm{JCO}$ 사고 이후에도 조직 및 문화 관 련 문제가 해결되지 않고, 몬주로 화재 사고와 동경전력의 거듭된 허위 보고 및 은폐 등으로 문제가 계속 잠복되었다 가, 2011년 후쿠시마 사고를 통해 드러남으로써 원자력에 대한 근본적인 불신에 봉착하게 된 셈이다.

원자력 분야에서는 대부분의 사고를 근본적으로 인적오류 로 보는 관점을 유지하고 있을 뿐만 아니라, 체르노빌 이후 에는 그 원인이 조직적 문제까지 확대하고 있다. 그럼에도 불구하고 일본은 체르노빌 사고에서 제기된 안전문화 문제 를 $\mathrm{JCO}$ 사고를 통해서 직접 겪었음에도, 이후 조직 및 문화 적 문제를 반복하면서도 후쿠시마 사고에 이르기까지 적절
한 대응방안을 확립하지 못하고 있었다.

\subsection{A revisit to the JCO criticality accidents in Japan}

1) $\mathrm{JCO}$ 사고의 원인과 대응

$\mathrm{JCO}$ 사고는 작업자가 임계가 발생하지 않도록 정해진 규칙을 위반하면서 과도한 양의 우라늄 을 처리하려고 했기 때문에 발 생한 것으로, 단순한 작업자 위 반(violation) 유형의 인적오류 사고로 해석되었다(일본원자력 안전위원회보고서 기준). 또 이 어지는 비상대응 과정에서도 일

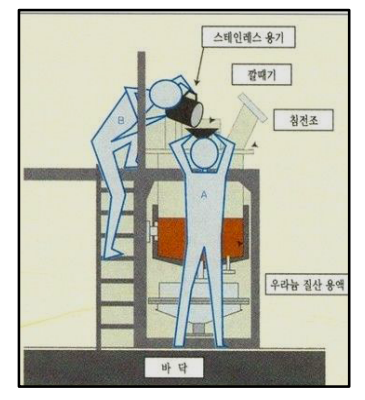
부 실수가 추가로 지적되었다. 그 결과 피폭된 종사자를 포 함한 JCO 직원 6명에 대한 벌금형 및 형사처벌로 이어졌으 며, 후속조치로는 사고 후의 문제를 중심으로 방사선 사고에 대한 일본 정부의 비상대응 계획을 보완하는 것이 고작이 었다.

그러나 작업자가 그런 치명적인 위반을 저지르게 된 이유 에 대한 의문이 제기되어, 공정 및 절차의 무단 변경과 위반 을 지속해온 관행은 물론 임계의 위험에 대한 종사자의 무지 와, 적절한 위험지식을 제공하지 못한 관리가 직접적인 원인 으로 지적되었다. 또 그런 원인의 배경에는 $\mathrm{JCO}$ 경영자, 주 문을 주도한 $\mathrm{PNC}$ 및 원자력 규제 당국의 전문가적 과신과 잘못된 판단이 있으며, 이들은 모두가 일본의 고유한 조직 및 문화적 특성으로 인해 문제점으로 작용한 것으로 지적되 었다.

Figure 6은 $\mathrm{JCO}$ 사고에 대한 최초의 공식 보고서 원인분 석 결과에, 이외에도 언론과 논문 등 15 가지 국내외 문헌에 서 제기된 원인 및 영향요소들을 사건 발생 전후로 나누고 관련 주체들을 구분하여 구조적으로 재구성한 것이다.

우선 의도치 않은 임계를 야기한 작업자의 위반작업은 작 업자 개인이 알려진 위험을 무시한 위반 행위가 아니었다. 작업자들은 임계 위험에 대해서 전혀 알지 못했을 뿐만 아니 라, 그런 위험 상황이 발생할 수 있는 잘못된 공정 및 절차 가 있었다. 잘못된 공정 및 절차는 $\mathrm{JCO}$ 에 의해 이미 사고 5년 전에 임의 변경되었다.

따라서 종사자에 대한 교육훈련 부적절, 형상관리 부재 등 의 조직적 결함을 넘어, $\mathrm{JCO}$ 운영의 결함과 이를 지속한 관 행이 진정한 원인이다. 나아가 $\mathrm{JCO}$ 의 운영에 근본적인 결함 이 생기고 사고가 발생할 때까지 지속된 것은, 영리기업인 $\mathrm{JCO}$ 의 운영에 걸맞지 않는 핵연료공단 $(\mathrm{PNC})$ 의 무리한 주 문(고농도의 균질화된 액상 우라늄)과 상업조직과 유착된 일본 규제기관의 부적절한 승인체계 및 승인 후에는 책임을 

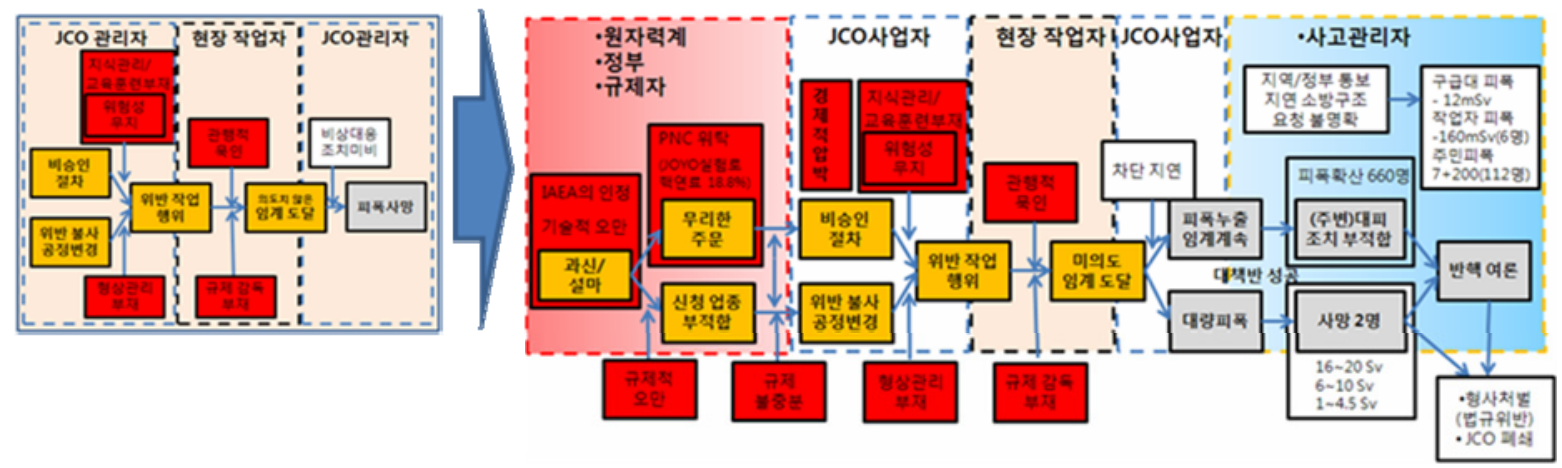

Figure 6. A restructuring of the JCO accident according to the related reports

위임하는 관리감독의 소홀 등이 근본원인이었다.

물론 이들의 배경에는 일본 원자력계의 기술적 자만심에 서 출발한 '설마 의식'과 IAEA로부터 핵연료주기기술 전반 을 인정받아 재처리까지 이행하게 된데 따른 '자기과신(자만 심)'이 자리잡고 있는 것으로 재분석된다. 이들은 JCO만의 문제가 아니라 일본 원자력계의 근원적인 문제에 해당하는 포괄적인 항목들이다.

이러한 조직 및 문화적 문제는 사건의 발생 후 대처 과정 에서도 동일하게 작용했다. 20시간 동안 임계를 종식시키지 못한 것은 기술능력의 부족 이외에도 기술적 의사소통 능력 의 결함을 드러낸 사건이었다. 방사선 시설에서 비상계획 의 미비 및 피폭 사고에 대한 의사소통 실패 등도 피해 확산 의 원인이었다. 구조반/대책반에서 불필요한 피폭이 지속되 고 신속한 대처 및 비상대응 능력 부족으로 사회적 혼란 및 반핵 여론을 촉발한 것은 여전한 일본식 폐쇄적 문화와 조직 문제 때문이었다. 이는 체르노빌 사고와 동일하게 JCO 사고 에서도 안전 의사결정 및 의사소통의 부족과 같은 조직 및 문화적 문제를 드러낸 것이다. JCO 사고를 분석하면서 일본 도 이러한 문제를 원인으로 지적하고, 대응조치의 필요성을 심각하게 제기한 것으로 보인다.

\section{2) $\mathrm{JCO}$ 사고의 원인 재구성 및 대응방안의 재검토}

$\mathrm{JCO}$ 사고와 관련하여 다수의 문헌에서 조직 및 문화 측면 과 관련된 대부분의 요인들이 심각한 원인으로 파악되고 반 복적으로 제기되었지만, 대응방안과는 상당한 거리가 있었다. $\mathrm{JCO}$ 운영조직의 안전 불감증과 그로 인한 공정 및 절차의 무단 변경이나 이를 방관한 규제기관의 문제를 인정하였음 에도 불구하고, JCO 사고의 후속조치는 제한적이었다. 예를 들면 일본의 안전문화 문제나 규제기관과 원자력계의 기술 적 유착성 문제에 대해서는 아무런 실제적인 조치가 없었다. 대신에 JCO 종사자를 개인적으로 처벌하는 책임추궁 방식 의 전형적으로 잘못된 인적오류 대응방안과 문제의 원천인
$\mathrm{JCO}$ 공장을 아예 폐쇄하여 논란을 회피하는 방식의 회피형 대응조치만을 실행하였다.

\section{Safety Culture Lessons Learned from the Recent Human Error Cases in NPPs}

사고를 설명하는 전통적인 모델인 Casual Sequence 모델 에 따르면, 모든 사고는 여러 요소들이 연쇄적으로 연결되어 일어나는 것으로 설명하고 있다. 한 가지 원인만으로 사고가 일어나는 경우는 없으며, 개별적으로는 건전할 수도 있는 여 러 요소들이 연쇄 반응의 구조로 연결되어 최종적으로 종사 자의 불안전 행위 (Unsafe Act)를 유발시키고, 종사자의 불 안전 행위가 직접 인적오류는 아니더라도 시스템의 거동과 결합되어 손실(loss)이 있는 결말(consequence)로 발전함 으로써 사고가 발생한다는 것이다. 이는 Reason의 '스위스 치즈 모델'에서 보다 구체적으로 설명되어, $\mathrm{HFACS}$ 에서는 1) 불안전 행위, 2) 불안전 행위의 전제조건, 3) 불안전 감독, 4) 조직의 영향 등 4 가지 수준과 17 가지 유형의 원인요소 로 구조로 발전하였다(Shappell \& Wiegmann, 1997). 그 러나 몇 가지 요소들의 고정된 구조로 다양한 인적오류의 형태 및 안전문화 요소를 설명하기에는 충분하지 않다.

\subsection{Discussions on the Lessons from Kori\#1 SBO case}

조직 및 문화 측면과 관련된 대부분의 요인들이 이미 심각 한 원인으로 제기되어 있었지만, 종사자와 관련된 조치를 제 외하고 실제 안전문화 관련 문제들은 대부분 구체적인 대응 방안으로 연결되지 못한 것이 특징이다. 이는 조직 및 문화 적 요인을 단순히 포괄적인 '안전문화 결함'으로 치부하고, 구체적인 오류의 구조를 분석하지 않았기 때문이다. JCO 운 
영조직의 안전 불감증과 그로 인한 무단 공정 및 절차 변경 이나 이를 방관한 규제기관의 문제에 대하여, 규제기관의 기 술적 유착성은 구체적인 조치가 불가능한 문제로 보고 대신 $\mathrm{JCO}$ 조직을 아예 폐쇄하는 극단적인 책임추궁으로 대처하 였다. JCO 사고의 원인 중에서 종사자 및 운영회사의 위반 행위에 대한 처벌은 엄격한 관리의 뉘앙스를 제공했지만, 실 제로 일본 원자력 분야에서 그 효과는 거의 없었던 것으로 보인다. 특히 $\mathrm{JCO}$ 와 같은 핵주기 시설과 원전을 분리하여 원전에 적극적인 조직문제 대응조치를 적용하지 않았기 때 문이다. JCO 사고 이후에 몬쥬 고속증식로 누출화재사고, 미하마 원전 고온증기 사망 사고, 동경전력 허위 보고 및 은 폐 등이 발생하여, 보다 엄격한 관리와는 완전히 동떨어진 상태가 계속됨을 증명하는 사건들이 연이어졌기 때문이다.

더욱이 그런 조직 및 문화 문제가 배경원인으로 지속되고 있음을 인식하였음에도 불구하고 후쿠시마 사고가 발생하기 까지 일본은 이 분야에 대한 적극적인 조치에 나서지 않은 것으로 추정된다.

예를 들면 $\mathrm{JCO}$ 의 인허가 과정에서 규제기관과 사업자와 의 유착관계는 후쿠시마 사고에서도 동일하게 지적되었다. 또 JCO사업자/비상조직/정부간의 의사소통 및 의사결정 실 패는 후쿠시마 사고에서도 동일한 문제로 작용하여, 사고의 진행을 효과적으로 완화시킬 기회를 놓치고 전세계적인 불 안감을 고조시켰다. 특히 알려진 근원적 위험에 대해 사고 이전에 조치할 수 있었다는 지적은 통렬한 것이었다. 또 상 대적으로 폐쇄적인 일본의 조직문화적 특성은 후쿠시마 원 전 및 동경전력의 기술적 책임감을 통해 효과적인 위험 의 사소통을 차단하여, 오히려 사태를 악화시킨 전문가적 오만 으로 지적되었다.

\subsection{A retrospection of the JCO case for safety culture}

원전 사고에 대해 인적오류 측면의 분석을 통해 효과적인 안전대책을 수립하는 것은 이제까지 유익한 결과를 도출하 였다. 그러나 JCO 사고의 교훈학습과정을 살펴보면 조직 및 문화적 요인의 경우에는 인적오류 분석이나 대응방안 도출 에서 효과적으로 다룰 수 있는 방안이 불확실하여, 사고의 교훈에서 직접적인 개선을 기대하기는 아직 어렵다.

일본은 $\mathrm{JCO}$ 사고에서 드러난 조직 및 문화적 문제에 대 하여 이후 동향 및 후쿠시마 사고로 보아 적절한 기술적 반 영에 결과적으로 실패한 것으로 보인다. 그런데 이러한 동향 은 불행히도 국내 원자력 분야에서도 유사한 상황으로 추 정되는 형편이다. 국내에서는 JCO 사고와 같은 대형피폭사 고는 발생한 적이 없으나, 원전화재, 백색비상 지연발령, 밸 브해체 작업 중 화상 사고 등과, 최근에는 시험 중 격납용기 살수(containment spray), 완전전원상실 및 은폐로부터 납
품비리에 이르기까지 등 다양한 문제가 발생하여 조직적 문 제에 관심이 집중되고 있다. 특히 한국형 원전이 본격 가동 되기 시작한 2000년대의 불시정지 사건을 재분석한 결과 $70 \%$ 이상 절대적으로 큰 비중의 사건이 조직적 문제와 관 련이 있는 것으로 분석된 바 있다(Kim, S.K. et al., 2012). 이는 일본과 유사하게 조직 및 문화의 결함에 대한 구체적인 인식 및 대처에 실패한다는 의심을 피할 수 없다.

예를 들면 최근 국내에서 발행된 후쿠시마 사고 보고서에 서도 안전문화 문제를 강조하고 있으며, 국내 스스로 채택한 교훈의 5 가지 분야 중 안전철학 및 확보체계 강화, 안전기반 강화 등 2 개 분야에서 안전문화와 관련된 문제를 제기하고 있다(KNS, 2012). 그러나 대응방안은 결과적으로 '안전문 화가 체질화되고 독립적으로 평가되어야 한다'는 포괄적인 선언에 그치고 있으며, 구체적으로는 규제기관의 독립성/전 문성 또는 운영기관의 책임을 다시 강조하는 수준에 머물고 있다. 상대적으로 중대사고 연구나 안전감시기능의 보강, 비 상대응 체계의 강화 등에서 제시되는 구체적인 조치와는 달 리, 조직 및 안전문화 관련 조치는 굳이 후쿠시마 사고와 직 접적인 연관을 짓지 않아도 되는 일반적인 교훈에 그치고 있다.

인적오류의 주요 원인으로 안전문화를 빈번하게 부각하고 있으나, 안전문화는 단일한 원인요소가 아니므로 전통적인 분석방법으로는 접근이 어렵다. 인적오류는 상황종속성을 고 려하여 구조적으로 정의되어야 하기 때문에, 안전문화는 별 도의 원인요소로 포함되는 것이 아니라 요인간의 구조에 내 재되는 성격을 가지고 있다. 또한 대응방안 도출에서도 안전 문화를 포괄적으로 개선 또는 증진해야 한다는 것은 구체적 인 내용을 적시할 수 없으므로 대응방안으로 유효할 수 없다. 발생된 사건으로부터 안전문화의 결함을 의미하는 구체적인 내용이 사건의 세부요소와 그들간의 구조로 나타나기 때문 에, 포괄적인 안전문화 개선이 아니라 특정한 측면에 대한 조치가 대응방안으로 선별되어야 할 것이다. 마지막으로 인 적오류 사건은 전형적인 대표성을 가지고 있는데, JCO와 같 이 비원전 시설에서 발생한 사건이라고 하더라도 구조적으 로 동일한 다른 사건의 교훈으로 포착하는 대표성 분석이 필요하다. 이는 희귀 사고(rare event)의 특성을 가지고 있 어서 사고의 교훈이 귀중하게 취급되는 고신뢰도 체계의 인 적오류 관리에서 반드시 적용되어야 할 기술적 주안점이다.

특히 대응방안 도출과 관련해서는 인적오류 분석자들 대 부분이 신중하지 못하거나 기술적 오해로 인해 조직 및 문 화 문제와 같은 미묘한 요소를 다루기에는 현저히 취약한 것으로 보인다. 우선 인적오류는 단일한 원인과 결과의 조합 이 아니므로, 특정한 원인요소를 여러 사례에 걸쳐 그 빈도 와 비중을 종합하는 방식으로는 인적오류에 효과적으로 대 처하기 어렵다. 인적오류는 반드시 다양한 요소들의 조합으 
로 파악되어야 하는 하나의 사건이기 때문이며, 조직 및 문 화의 결함의 경우에는 대부분 그러한 조합을 나타낼 수 있 는 구조로 분석되어야 하기 때문이다. 또한 인적오류의 원인 이 그대로 대응방안으로 직결되지 않는다는 점에서 현실적 인 선택에서의 효과를 관리하기 어렵다. 조직 및 문화 요소 의 경우에는 문제를 직접 해결하거나 통제하기 보다는 영향 관계를 통해 간접적으로 대응하는 것이 비용-효과 측면에서 더 효과적이기 때문이다.

현재로는 이러한 관점을 반영하여 인적오류를 신중하게 다루고 있는 기법은 아직 발견되지 않는다. 인적오류 분석에 서 조직 및 문화 문제의 분석 및 대응이 적절하지 못했던 것 은 이상과 같은 인적오류의 종속성, 구조성, 대표성 등 기본 특성을 반영하여 안전문화에 대한 바른 접근방법에 따른 분 석 및 대응방안 도출 기법이 없었기 때문이다.

\section{Conclusions and Discussions}

본 논문에서는 국내 원자력 분야의 인적오류 방지에 필요 한 고려사항을 도출하기 위하여, 1999년 JCO 핵연료 가공 공장 임계 사고를 중심으로 일본의 인적오류 교훈사례 학습 과정을 검토하고, 이를 기준으로 국내의 고리 1 호기 전원상 실 $(\mathrm{SBO})$ 사건 등을 재검토하였다. 인적오류 분석 및 대응 방안 도출에서 조직 및 안전문화 문제의 분석 및 대응이 적 절하지 못했던 것은 일본만의 문제가 아니었다. 이는 그동안 인적오류의 종속성, 구조성, 대표성 등 기본특성을 반영하는 기법이 미진하고, 대책 중심의 실무적 필요에 초점을 맞춘 효과적인 인적오류 분석 접근방법과 새로운 현안에 대한 분 석기법의 개발이 상대적으로 미진한 상태에 머물렀기 때문 이다.

일본의 $\mathrm{JCO}$ 사고 및 그 교훈학습의 실패 경험은 지구 온 난화 및 환경문제와 UAE 원전 수출로 원자력 르네상스의 재래를 구가하다가, 최근 고리 1 호기 전원상실 및 은폐, 원 전 납품비리 등 몇 가지 사건을 통해 신뢰성에 의심을 받고 있는 국내 원자력 분야에 시사하는 바가 동일한 맥락임을 드 러냈다. 안전 전반에서 우월적 자부심을 유지하던 일본이 $\mathrm{JCO}$ 사고에서 드러난 문제에 제대로 대처하지 못하고, 연이 은 은폐와 허위 보고 등을 경험한 후에도 같은 문제로 후쿠 시마 사고를 당한 점은 중요한 타산지석이다.

그러므로 인적오류 분석 및 대응방안 수립 과정에서 조직 및 안전문화라는 새로운 과제를 다루는데, 일본의 시행착오 경험을 적극 반영한 접근방법에 대한 본격적인 논의가 필요 하다. 또 이를 기반으로 조직 및 문화적 문제와 관련된 인 적오류의 대처를 위한 기법 개발이 시급하다. 원자력 분야에
서는 조직 및 문화적 측면에서 인적오류를 분석하고 이에 대 처하기 위한 다양한 기법을 개발하기 위한 노력이 시작되고 있다.

인적오류의 대응은 사고사례와 아차사례 분석 등 회고적 분석 과정에서 분야별 유형 및 근본 배경에 대한 포착이 이 루어져야 한다. 특히 배경요소인 조직 및 안전문화와 관련된 위험요소가 관련될 경우, 이러한 정보를 조직 내의 구성원들 에게 적극적으로 전파하여야 하며, 이를 토대로 동일하거나 유사한 사고사례가 발생하지 않도록 하는 선순환적 접근방 법이 필수적이다. 이를 위해서 조직 및 안전문화 관련 인적 오류 사고는 사고조사 시 객관적인 원인분석뿐만 아니라 배 경의 위험요소 포착에 집중하여, 귀중한 교훈을 도출하는 과 정을 포함해야 한다. 특히 희귀사고의 특성을 가진 고신뢰도 체계에서 발생한 인적오류 사건은 조직 및 안전문화와 같은 깊숙한 위험요소의 실체를 포착하여 근본적인 신뢰감을 상 실할 수 있는 대중의 인식 악화에 대비할 수 있는 값비싼 기회라고 할 수 있다.

\section{Acknowledgements}

This research was supported by the nuclear energy research and development project(Grant. 2012M2A8A-4004256) funded by the Ministry of Education, Science and Technology.

\section{References}

Cha, J.H., Nuclear Safety: Tokaimura JCO Criticality Accident, KAERI, (reference source - http://www.nuketext.org/jco.html)

IAEA, Preliminary International Incident Report, IRS\# 8229, 26 April, 2012.

IAEA, The Management System for Facilities and Activities (Safety Requirements), IAEA-GS-R-3; 2006.

KHNP, Loss of Offsite Power and Emergency Diesel Engine Failure, (09 February 2012, Kori Unit 1, KHNP), Interim Report, 17 June 2012.

Kim, S.K. et al., Investigations on Human Error Hazards in Recent Unintended Trip Events of Korean NPPs, Transactions of KNS2012-Fall, 2012.

KNS, A Report on Fukushima Accident (summary) (in Korean), 2012.

Lee, Y.H., A Review on the Human Error Research Issues from the Recent Events in Nuclear Industry, Proc. ESK 2011 Spring, 2011.

Lee, Y.H., A Revisit to the Japanese Cases of Nuclear Accidents for Human Error Analysis and Countermeasure Development, Proc. ESK 2012 Fall, 2012. 
Lee, Y.H. et al., An approach to find countermeasures against human errors in NPPs, Proc. NPIC\&HMIT 2009, USA, 2009.

Lee, Y.H. et al., A Preliminary Study on the Cultural Differences between Korean and Japanese Nuclear Power Plant Organizations, Transactions of KNS Fall, 2011.

NSC, An investigation report on the accident occurred in Tokaimura Uranium Processing Facility (1999.12.24) (in Japanese), NSC, 1999.

Reason, J., Human error. New York: Cambridge Univ. Press, 1990.

Shappell, S. \& Wiegmann, D., A human error approach to accident investigation: The taxonomy of unsafe operations. Int. J. of Aviation Psychology, 7, pp.269-291, 1997.

WANO, Loss of Offsite Power and Emergency Diesel Engine Failure (09 Feb. 2012, Kori Unit 1, KHNP), WANO Event Analysis Report EAR TYO 12-002, 2012.

Web-page (http://nsc.jst.go.jp/anzen/sonota/nscnews_jcof.htm), 1999.

\section{Author listings}

Yong Hee Lee: yhlee@kaeri.re.kr

Highest degree: Ms, Department of Industrial Engineering, Seoul National University

Position title: Section Head, I\&C and Human Factors Division, Korea Atomic Energy Research Institute (KAERI)

Areas of interest: Human-Machine Interface, Human Error, Cognitive System Engineering

Date Received : 2013-01-24

Date Revised :2013-01-28

Date Accepted : 2013-01-31 